\title{
DEVELOPING MASTER'S STUDENTS SCIENTIFIC COMMUNICATION SKILLS IN THE RUSSIAN AND ENGLISH LANGUAGES: MODEL, CONTENT, EXPERIMENT
}

\author{
N.I. Kolesnikova, Yu.V. Ridnaya
}

\begin{abstract}
The article considers the problem of forming and developing master's students scientific communication skills in the Russian and foreign languages. The authors focus on the culture of written scientific speech, performing accumulative and transmitting functions, which is complex, but is especially important for cultivating and developing learners' personality. The topicality of forming and enhancing genre competence as an important component of professional communicative competence is emphasized in the article. The authors propose courses for students in order to develop the competences at master level. The courses "Scientific Speech for postgraduate students" in Russian and "Foreign language (English)" are designed in accordance with learners' communicative and activity needs and the requirements of the Federal State Educational Standard of Higher Education. The principles being methodological basis of the course are described. The content and topics to study in the framework of the courses are given in detail. The methodology used involves the use of typological models of scientific genres and Intergenre Model of Scientific Text that includes invariant and universal components corresponding to the stages of communicative and cognitive activity of a scientist: case - problem - idea - hypothesis - argument - conclusion. The results of an experimental course teaching are presented. The effectiveness of the proposed methodology is confirmed.
\end{abstract}

Keywords: Russian and foreign language; master's students; scientific communication skills; typological models of scientific genres; intergenre model; subgenre.

\section{Introduction}

In the context of the increasingly globalized world, to succeed in professional and scientific activities, a modern graduate of a master's program must have not only specialist skills, but have good communication skills allowing to conduct research on the basis of domestic and foreign achievements, to share ideas and experience with colleagues, to publish articles and give presentations.

Moreover, Masters of Engineering, Economics and Humanities programs, must know how to use abstracts, periodic publications and reference books in their fields. They must be able to organize data and summarize information, to describe experiments, to prepare reviews and reports on issues in professional area. They must be able to edit, summarize, review texts, in other words, they should master written and oral genres of scientific information. 
Thus, developing scientific communication skills, both written and oral, is becoming an important component of professional training at universities in Russia. It is a crucial issue, so instructors and lecturers of History, Philosophy, Law, Psychology, Economics, Social Sciences and Engineering and Technology try their hands at developing teaching guides and running courses teaching how to write scientific works of various genres. These are educators who are involved in education process checking up and marking course works and summaries, and supervising research activity of postgraduate students. The drawback of the teaching manuals and guides is their focus on the work format and the procedure of its defence rather than forming and/or developing linguistic, stylistic, text, genre competences of postgraduate students in scientific sphere of communication.

The development of genre competence in scientific sphere of communication has a huge impact on the formation of a specialist as the language personality and is the cornerstone of his/her professional competence.

There is a growing body of literature that recognizes the importance of mastering scientific genres that tends to be the basis for the language personality to feel competent in professional area and feel confident at any stage of continuous education, to learn independently, to develop creative abilities [1-5].

Consider one more incentive to master scientific genres. There is a growing tendency for international contacts in social and political, economic and cultural areas to expand and deepen. Hence, to be integrated successfully into the world scientific and professional community, a specialist should have a good command of English, which performs many functions to date: the language of international communication, a tool for searching and receiving new knowledge, a keeper of information in the World Wide Web, a working language of many international conferences and the language of publication in most foreign scientific journals. Besides, the fact that the English language is considered to be a necessary condition for a successful entry of an individual into the world's economic, political and cultural areas, in the context of multilingual teaching, teaching scientific communication skills in English is the developing skills in the language of worldwide communication used for overcoming interlingual and intercultural barriers in the globalized world [6].

Publication of research findings in English in foreign periodicals, indexed in information-analytical systems of scientific citation, opens up opportunities for the realization of students' and specialists' potential and participation in solving urgent problems of the international scientific community. Also, increasing the publication activity and quality of publications requires a Master to demonstrate the genre competence in a foreign language, in English in particular, that is to know the peculiarities of the English scientific discourse and the models of relevant scientific genres.

Moreover, the Federal State Educational Standard of Higher Education requires a graduate of a master's program to be able to generate a number of 
written and oral scientific genres in Russian and English in the framework of research activity.

Thus, a genre approach to teaching the Russian and English languages at master level is of great importance. According to the genre approach, the process of text-building involves not only the selection of lexical, grammatical and stylistic units and considering extralinguistic factors but the selection of a genre as a real unit of communication [7] corresponding to its goals.

Under these conditions a Master has to have a good command of foreign language, in which it is hardly possible to form the skills that had not been initially developed in the native language [8]. Fyodor Dostoyevsky wrote that "only after acquiring initial material, that is the native language, we are able to master a foreign language, not earlier" [9: 8].

However, the analysis of current text books and teaching manuals and guides for master's students shows that they do not take into account the learners' needs in mastering genres in a foreign language which is necessary for research activity.

Thus, the need for real mastering a foreign language that has significantly increased in modern education and society, the need for increasing the publication activity and the quality of scientific publications, the requirements of the Federal State Educational Standard of Higher Education to professional training of Masters of Engineering and Technology programs, on the one hand, and the lack of a methodological model of teaching aimed at forming the genre competence of Masters of non-linguistic programs to make them feel competent implementing discursive activities in a foreign language (English), on the other hand, determine the relevance of this study.

\section{Methods}

The scientific and theoretical background of the study is composed of findings of domestic and foreign linguists, psychologists, philosophers, educators, methodologists. Moreover, the article is based on the principles, methods and techniques relevant to the modern methodological theory and best practices for the development of students' scientific communication skills and speech culture. The authors rely on the most important philosophical statements on the social and pragmatist nature of man, on the unity of empirical and theoretical approaches to scientific research and training.

The main methods used in the study are the experiment, observation of the process of students' mastering various scientific genres, the study of best practices for teaching Speech Studies and Rhetoric in Russian and foreign languages; modeling of scientific texts and their genre varieties (creation of educational schemes or algorithms); theoretical analysis of linguistic and methodological literature and the existing classifications of scientific genres, written academic and scientific texts of different genres produced by 
students of non-philological programs at Bachelor's and Master' levels; synthesis method that involves combining genre classifications into a single educational and methodological system; comparison method that allows to establish similarity and difference in communicative and activity needs of Russian students of different programs (Engineering, Humanities, Economics, etc.); questionnaire method used for questioning undergraduates, graduates, postgraduates, as well as lecturers of Speech Studies and special disciplines in order to confirm / disprove the assumptions considered in the study; statistical method used for the analysis of texts of higher school textbooks on the Russian Language and Culture of Speech, EFL textbooks, processing data obtained in the study, and the results of questionnaires.

The dominant principles of forming genre competence in scientific communication sphere in English are as follows: the principle of comparative learning and teaching, native language effect, cognitive principle, individual study, visibility principle, principle of scientificity, intrinsic motivation, field of study effect, interdisciplinary and integrated learning, module teaching, communicative approach, ICTs in teaching and learning, andragogical approach.

While developing the teaching model of forming genre competence, there were considered the following factors: special characteristics of developing master's students communication skills, engineering cognitive style of master's students of engineering programs, the algorithm of forming genre competence evolving gradual stages of work to teach master's students how to create various scientific genres in a foreign language, the typology of exercises aimed at learners' mastering secondary and primary genres and taking into account peculiarities of creating these genre varieties in English.

Notion of a primary scientific genre was offered by Bakhtin who was the first to distinguish between primary and secondary genres. According to his classification, primary genres are those that are formed actually in communication. Secondary genres by Bakhtin are the synthesis of primary ones that are transformed losing their reference to reality and are kept as a part of compound (secondary) genres [7]. As for scientific communication, scientific genres are divided into primary and secondary genres in accordance with the principle of information exposition that is reflected in opposition "primary data vs analytic and synthetic processing". So, primary scientific genres are those that contain or present information / data / findings obtained as a result of scientific research (e.g. scientific report / paper, thesis / dissertation, abstracts for a conference, etc.). Secondary scientific genres are the products of analytic and synthetic processing of primary scientific texts (e.g. summary, abstract to paper, review, etc.). Furthermore, they are obtained as a result of analyzing, paraphrasing, compressing, summarizing and other cognitive activities aimed at the transformation of primary text information.

An experimental teaching was conducted to evaluate the effectiveness of the developed methodology for forming foreign language genre compe- 
tence in scientific communication sphere of master's students. The foreign language genre competence in scientific communication sphere is considered as a scope of knowledge about stylistic peculiarities of a foreign scientific text and a variety of genre models; developed skills of creating different scientific genres in a foreign language in accordance with communicative task of intercultural scientific communication using appropriate linguistic and stylistic means. The experiment was carried out in groups of master's students of engineering programs at the faculty of Radio-Engineering and Electronics (Novosibirsk State Technical University, Novosibirsk (NSTU), Russia).The analysis of data received as a result of testing the experimental and control groups was carried out using the Mann-Whitney U-test [5].

\section{Results and discussion}

According to the life-long learning concept, the postgraduate level is a stage for forming, developing and extending learners' specialist scientific worldview, for sharpening self-development and self-study skills. It is the stage when students are ready for continuous enrichment of their individual potential. It is the stage of professional opportunities and realization in profession and carrier.

Master's students are supposed to be the category of learners who consider the master's thesis a spring-board for doing research at postgraduate level and defending consequently the dissertation for Candidate of science degree. So, to achieve the goal, we propose the course "Scientific Speech for postgraduate students". The course is developed and run on the basis of the following dominant principles:

1. Linear-concentric teaching and learning (Graduality principle). We suppose that learner's mastering scientific and academic genres at master level is much more successful provided it is preceded by forming and developing genre skills at high school and undergraduate levels in the framework of the module "Scientific Speech".

2. Intrinsic motivation principle and learner's needs. It is obvious that a university course "The Russian Language and Speech Culture" cannot fully meet the communicative and activity needs of postgraduate students. It is caused by motivation and purposive factors.

Unfortunately, most first-year students do not consider the perspective of Master's or Candidate's thesis defence. They think that some material of the course is ahead of time and boring. However, if there is no course like that in the curriculum at undergraduate level, master's students address a lecturer with a request to start with secondary scientific genres, e.g. summary, abstract, etc.

We discovered the needs of beginning researchers having studied the massages from the Internet forums for postgraduates [10]. Let us cite some 
of them: "Once I bring my adviser a draft of my article, he crosses it out, saying that the text is written not scientifically" or "The results of the latest meeting with my research adviser are as follows: he says that there will be a conference soon and I must submit an abstract for the conference. The communication ends on this. I am in a puzzle. Some requirements to the abstract format are given in the entry submission (number of pages, spacing, font, etc.). There are some questions. Is the title page required? Actually, the title page is needed everywhere... but... who knows? Is the reference list applied to an abstract?" (The final question caused heated debate on the forum. - N.K.).

How do textbooks take into account communicative and activity needs of postgraduate students? The analysis of current textbooks and teaching manuals and guides shows that these materials are developed by lecturers of Social Sciences, History, Psychology, Philosophy and mainly contain theoretical knowledge. The textbooks cover the following topics: the process of preparation and defence of dissertation, new documents defining the procedure of conducting research and defending Candidate's and Doctoral dissertations, the basics of methodology and philosophy of science, a computer as a tool for writing thesis, "the technology of "getting into" foreign scientific periodicals. The textbooks do not prepare for research work, they do not teach how to write articles and the text of dissertation. But an individual learner's experience seldom helps develop good writing skills.

To meet the communicative and activity needs of postgraduate students, the textbooks devoted to language and style of dissertation should be developed and published. These textbooks should be aimed at developing genre competence, teaching communicative and pragmatic (contentsemantic) structure of a scientific text, teaching structural models reflecting the direction of cognitive activity of a scientist, metatextual organization of scientific information, rhetoric of scientific communication, developing presentation skills, skills of holding a discussion in scientific community.

We consider that the main task for master's students in this case is to master core genres: abstract for a conference, article / paper and dissertation. They also have to extend their knowledge about some subgenres, e.g. abstract for dissertation, indicative writer's summary, summary - keywords, etc.

3. Taking into account the field of study. While teaching master's students in Russian, it is relevant:

1) to give lecturers and practical classes;

2) to take into account students' field of study.

The results of master's students' questionnaire underline the necessity of practical training using topics of a major subject.

4. Student-centered learning. Teaching a student how to edit a scientific text aims at developing his / her communicative competence. The process of editing involves a mature and thorough reading and learner's self-evaluation of the generated scientific text on the basis of style and 
genre norms. This kind of work allows forming a sense of author's responsibility and respect for scientific community as an addressee. The variety of students' interest and their errors in a scientific text do not let a lecturer spend most part of a lesson doing this kind of work, so tutorials can help solve this problem.

5. ICT in education. Master's students can receive materials for home and individual work using e-mail service. A computer used by students is an additional means for electronic text editing in this case. But the use of the spell checking feature of a word processor not always helps learners type stylistically correct texts. According to master's students, this feature is usually switched off as it disturbs students. So, students can use online dictionaries and recourses to edit their scientific texts.

6. Teaching optimization. It is necessary to consider three issues to optimize teaching process:

1) Position and role of the course "Scientific Speech" in the curriculum at master level.

2) Content of the course.

3) Course correlation in accordance with different number of credits earned by students of different engineering programs at different faculties.

The conducted experimental teaching showed that it is relevant to include the course "Scientific Speech" into the first year curriculum at master level. The content of the course is described below. The practical module of the course is mainly devoted to drafting and editing the introductory part of dissertation.

7. Cultivating personality. Forming professional communicative competence at master level must be aimed at cultivating personality by means of linguistic and stylistic repertoires. The educational synergetic effect can be achieved through the integration of teaching, developing and cultivating personality.

Postgraduate students of engineering programs are future university lecturers of specialist disciplines. Considering the fact that they do not study pedagogical disciplines to be prepared for teaching activity, it is important to pay special attention to cultivating personality of a future scientist and educator. They are those who will represent the national and Russian education in the nearest five decades. So it is important to pay special attention to fostering and encouraging the following learner's attitudes and beliefs:

- respect for a scientific adviser;

- goodwill and respect for colleagues and students;

- modesty, self-discipline;

- spirituality and moral attitude to the world;

- civil (patriotic) worldview;

- responsibility for their research to themselves and to society; scientific and work ethics (do not harm), humanity and honesty; 
- tactful behavior during scientific disputes and discussions, an ability to listen to and respect other people's point of view, culture of oral and written peer-reviews.

Comprehension of ethical experience of previous generations, cultivating patriotism and national pride in the achievements of Russian science can be realized using the texts about brilliant scientists of the past and the present, their messages to the youth. It is a lecturer's responsibility to build the learning process so that spirituality and morality will become the need for self-development of an individual. To perform the task it is important to attract learner's interest to the moral and ethical aspects of the course.

Experimental teaching of the course "Scientific speech" showed that it is possible to fully solve the problem of forming genre competence of master's students under the condition of continuous language education, including the pre-university and university levels of study. Also, it is essential for educators to distinguish the dominant principles and design an integrated educational program that ensures the continuity in training at each level of study [4].

Let us describe the topics discussed in the framework of the course "Scientific speech for postgraduate students" in the Russian language.

- Functional speech styles. Scientific style of speech. History of scientific style in Russia (a brief review).

- Functions of scientific style and its characteristic features.

- The main features of the scientific style. Substyles and corresponding subgenres. Sublanguages.

- Language of science. The use of elements of different language levels in scientific speech. Scientific terminology.

- Methods of information presentation in scientific text (description, narration, reasoning, definition, recount). Reasoning as an argumentative type of speech. Varieties of reasoning (i.e., pure reasoning, evidence, argumentation, exposition, validation).

- Structure of "narrative", "argument", "descriptive" paragraphs. Structure of "narrative", "argument", "description" micro-texts.

- Means of connection in scientific text. Two types of text content (elaborated and summarized). Variable repetitions as a means of scientific text organization.

- Requirements to a title. Citing styles.

- Categories of a scientific text (interlocutory, hypothetical, authorization, intertextuality, continuity of knowledge, evaluation, accentuation, etc.).

- The main properties of scientific text (connectivity, integrity, logic). Scientific text as a reflection of stages of a scientist's scientific and cognitive activity. Intergenre model of ascientific text.

- Genres of scientific literature. Genre variety of summaries and abstracts. 
- Notion and definition of a summary and summarizing. History of abstracting. The summary as a brief statement that gives the main idea of a primary text. Function and types of summaries. Bibliographic, popular science, academic and scientific summaries. Requirements for a summary. Summary and abstract. Abstract as a type of compressed characteristics of a primary text, its structural and linguistic features. Resume. The typical plan of a review of a scientific work (a subject of analysis, a relevance of the topic, an outline, a statement of the main thesis, an overall assessment, drawbacks, shortcomings of the work, conclusions).

- Dialogical genres of oral scientific speech (scientific discussion).

- Culture of oral discussion (oral review).

- Scientific research, its types (theoretical and applied) and stages (problem statement, data collection and data analysis, hypothesis, dissertation formatting, defence). Arrangement of research findings. The requirements of Higher Attestation Committee to the language and style of dissertations.

- The structure of a thesis and its components (Title Page, Content, Introduction, Chapters and Sections, Conclusion, Reference, Appendices, Index Terms).

- Format and content features of the master's research. Methods of compression of the thesis text. A typological model of a thesis as a genre. The subgenre 'Introduction to Thesis' as the text about the basis ideas of the research and a secondary text. Structural characteristic of the thesis components and their function in the introduction. Methodological structure of the introduction of a scientific work. Drafting, editing and writing the introduction of a thesis.

- Harmony of a scientific text. Stylistic uniformity of fonts, wording, headings and subheadings. Citation and bibliography formats (in-body citation, footnotes, etc.)

- Procedure, language and speech peculiarities of thesis defense.

- Model of report / presentation on the theme of the master's thesis during public defense at State Attestation Commission meeting.

- Etiquette of public defense of a scientific work. Speech behavior of an applicant in accordance with the communicative task (presentation of the content, persuasion of opponents, expression of agreement / disagreement, gratitude, culture of answering questions) [11].

In addition to the course in Russian mentioned above, we propose a course in English aimed at developing genre competence in scientific communication sphere in the frame of a master's program. The course "Foreign language (English)" is included into the curriculum at master level.

Before developing the course, need's analysis among master students was conducted. To define highly demanded scientific genres and the most important communication skills for a modern specialist in scientific sphere 
in a foreign language, a survey was conducted among the $1^{\text {st }}$ year master's students of engineering programs at NSTU, Russia. Besides, the survey was aimed at obtaining data on master's students' self-assessment of English scientific language functions. It is recommended to carry out the survey like this regularly in order to diagnose current student's communication and activity needs in a foreign language for the purpose of further revision of the course and its redesign, if it necessary.

It is worth mentioning that a steady change in the requirements of the Federal State Educational Standard of Higher Education to graduates of current master's programs in engineering causes regular 'update' or 'reset' of courses.

The master's students surveyed are normally asked to indicate whether a certain communication skill in English is "very important", "not important", "difficult to answer" for a modern specialist. It should be underlined that these skills form a group of scientific writing skills. The students were also asked to indicate their level of proficiency in scientific genres in English according to a 5-point scale. The results of recent survey are as follows:

- most master students surveyed - $84 \%$ and $80 \%$ consider the skills" writing a full paper" and "writing abstracts for a conference" respectively to be "very important" for modern specialists;

- the skill "to write a resume" is evaluated as "very important" by $64 \%$ respondents;

$-70 \%$ of the master students rate as "very important" the following skills: "writing an abstract to paper" and "writing a summary";

- the lowest figure (42\%) is the number of master's students who consider the skill "writing a review" to be "very important ";

As for master's students' self-assessment, the figures obtained are as follows:

- $62-74 \%$ of the respondents tend to rate from 3 to 5 the skills, for example "writing abstracts for a conference", "writing a full paper", "writing an abstract to paper", "writing a summary", and "writing a resume";

- the figures show that the skills "writing a full paper" and "writing an abstract to paper" had not been mastered by $38 \%$ and $54 \%$ of respondents, respectively, who rated these skills as 1 and 2 points.

Thus, interpreting the results of the survey described above we can come to conclusion that there is a positive tendency in terms of the skills "writing a full paper" and "writing abstracts for a conference" since more master's students tend to rate these skills as "very important" for a specialist in comparison with the previous study [12]. Moreover, the number of students who evaluate their own level of proficiency in scientific genres in English is higher. Consequently, we can consider the genres of research report / paper and abstracts for a conference to be highly demanded in professional scientific communication. 
Consider the methodological background of the course developed. The dominant principles of the course are as follows: (1) The principle of comparative learning and teaching. It is implemented by means of comparative learning of facts and phenomena of foreign and native culture to reveal similarities and differences in terms of language, genres, ethic, etc. (2) The principle of bilingual learning or the principle of learning and teaching based on learner's native linguoculture. According to the principle the knowledge acquired and skills developed in a native language are effectively used by students mastering a foreign language. A lecturer's task in this case is to use a positive effect of the interlanguage interference while teaching. (3) The principle of interdisciplinary and integrated learning and teaching. It implies that the development of communicative competence is accompanied by the extension of informational, academic, social competences and the integration of knowledge from different disciplines.

To form and develop foreign language communicative and genre competences of master's students / masters, we propose to use the Intergenre Model of Scientific Text as a cornerstone component of teaching scientific genres in English [13]. The model is based on the cognitive theory and the four-level model of a cogniotype [14]. Teaching genres and text-generating activity, it is necessary to take into account the following theses: 1) scientific communication is aimed at reflecting the process and results of collective study in scientific texts; 2) scientific text possesses universal features of textbuilding model and provides scientific succession 3) scientific text conveys the mental phases of new knowledge development from problem and hypothesis to conclusion. The developed model contains invariant and universal components corresponding to the stages of communicative and cognitive activity of a scientist: case - problem - idea - hypothesis - argument - conclusion. Moreover, due to the model, while genre-generating activity, a communicant (a master's student or a Master) can easily put the genre components (text-building functional and semantic units of a genre) in the proper order to control the attention of another communicant or addressee. Within the Intergenre Model of Scientific Text we distinguish the following subgenres: 1. Topic of Study. Importance of Study. 2. Background of Study. 3. Lack of Knowledge. 4. Focus / Problem of Study. 5. Description of Methods and Techniques, Equipment and Materials, Experimental Conditions and Procedure. 6. Results. 7. Significance of Results / Study.

The proposed Intergenre Model of Scientific Text can be considered as invariant and universal as its subgenres manifest themselves in semantic and compositional structure of most scientific genres (e.g. abstract for a conference, abstract to paper, introduction to paper, scientific paper) $[4,5]$.

As for the course structure, it consists of three main modules: (1) Scientific Literature, (2) International Conference, (3) Scientific Paper. The module structure allows to adapt the course to two- and three-semester sylla- 
bus in a foreign language. Let us describe the modules content and communication skills developed.

Module 1 includes the following topics: Language and stylistic features of the English scientific text. Genre variety of English scientific literature. Secondary and primary scientific genres and their genre characteristics. Abstract and summary as secondary genres. Selection of scientific papers on a master's student's study. Writing a summary of a scientific paper. International information-analytical systems of scientific citation. Citation and bibliography formats. Citation Styles in English. Literature review on the topic of study. Writing the subgenre "Background of study" of "Introduction".

Module 2 covers the following topics: International scientific contacts. International conferences sites on a master's student's field of study. Participation in a conference. Abstract submission requirements. Genre characteristics of an abstract for a conference. Writing an abstract for a conference. Presentation skills and useful language. Oral presentation on the topic of a master's student's study. Conducting a scientific discussion and participating in it.

Module 3 contains the topics like these: Semantic and compositional structure of a scientific paper. Selection of a scientific journal on the field of study. Paper submission requirements. Model of a scientific paper. Language peculiarities for formulating: the theme and aim of scientific research, experiment conditions, methods and techniques, results and findings interpretation, tables and graphs labeling, conclusion. Drafting, editing and writing a scientific paper on a master's student's study.

An experimental teaching of the course mentioned above was conducted in the experimental group among master's students of an engineering program at the faculty of Radio-Engineering and Electronics, NSTU. The development of master's students' foreign language communicative and genre competences in scientific sphere was based on the methodology involving the use of the Intergenre Model of English Scientific Text while teaching and mastering scientific genres. The experimental results were compared with the results of teaching students of the control group. The experimental and control groups were taught how to write scientific genres in English in accordance with a single syllabus describing final skills and competences graduates must develop. The experimental teaching was conducted on the basis of the following principles: equality in learners' language command at the beginning of teaching, equality in criteria for works assessment. A summary, an abstract for conference and an introduction to paper were evaluated for diagnostic, formative and summative assessment respectively. The analysis of data received as a result of teaching the experimental and control groups was carried out using the Mann-Whitney U-test.

Comparison of the results of teaching the experimental and control groups showed that performance indicators in the experimental group were a bit higher than in the control group after formative assessment. Summative 
assessment showed that performance indicators in terms of content, organization, vocabulary and language use in the experimental group were much higher than in the control group that confirmed the effectiveness of the methodology proposed.

\section{Conclusion}

At present to be successful in professional and scientific spheres a modern specialist, namely a graduate of master's programs of Russian universities, must have both professional and communication skills. The letter ones must be developed not only in Russian but in English which is a tool for intercultural communication, obtaining new knowledge, means of sharing ideas and findings at scientific conferences, overcoming interlingual and intercultural barriers in the globalized world. Hence, forming and developing professional communicative and genre competences in scientific communication sphere in the native, Russian, and the foreign language, English, at master's level are of great importance. The courses "Scientific Speech for postgraduate students" and "Foreign language (English)" proposed for master's students and designed in accordance with learners' communicative and activity needs and the requirements of the Federal State Educational Standard of Higher Education are meant to achieve the goal. Moreover, the courses are aimed at cultivating learner's personality and developing scientific communication skills that are essential for a successful entry of a master program graduate as a specialist, scientist and educator into the world's economic, political and cultural areas.

\section{References}

1. Antonova, L.G.: Obuchenie studentov-slovesnikov professional'no znachimym pis'mennym zhanram [Teaching written genres essential for profession to philology students]. Abstract of Pedagogics doc. diss. M. (1998). (In Russian).

2. Aparina, T.A.: Obuchenie studentov nefilologicheskikh special'nostej pis'mennoj delovoj rechi v ramkakh kursa "Delovoye obshcheniye" [Teaching written business speech to non-philology majoring students as part of the course Business Communication]. Abstract of Pedagogics doc. diss. Yaroslavl. (2006). (In Russian).

3. Orlov, O.M.: Professional'no orientirovannaya ritorika: soderzhaniye i metodika obucheniya [Profession focused rhetoric: content and teaching methodology]. Pedagogics doc. diss. Saratov. (2003). (In Russian).

4. Kolesnikova, N.I.: Lingvodidakticheskaya kontseptsiya formirovaniya zhanrovoi kompetentsii uchashchikhsya $\mathrm{v}$ sisteme nepreryvnogo jazykovogo obrazovaniya [Linguodidactic concept of forming genre competence of students in the system of life-long language education]. Pedagogics doc. diss. Orel. (2009). (In Russian).

5. Ridnaya, Yu.V.: Formirovaniye inojazychnoj zhanrovoj kompetentsii magistrantov tekhnicheskogo profilya $\mathrm{v}$ nauchnoj sfere obshcheniya [Forming foreign-language genre competence in master's degree students of technical majors in scientific communication sphere]. Pedagogics. cand. diss. M. (2017). (In Russian). 
6. Smokotin, V.M., Petrova, G.I., Gural, S.K.: Teaching and learning English as the global language in the education systems of the globalized world // Language and Culture. 10. pp. 49-63 (2017)

7. Bakhtin, M.M.: Avtor i geroi. K filosofskim osnovam gumanitarnykh nauk [Author and hero. To philosophic basics of the humanities]. SPb. Azbuka. (2000). (In Russian).

8. Baranov, A.G., Vydro, M.S.: Printsipy obucheniya jazyku kak inostrannomu: Faculty, Competence, Heritage [Principles of teaching language as foreign one: Faculty, Competence, Heritage] // Mezhdistsiplinarnye aspekty lingvisticheskikh issledovanii: sb. nauch. tr. / pod red. V.I. Tkhorika, V.V. Katerminoi, A.M. Prima, A.V. Samoilovoi. Krasnodar: Kuban State University. pp. 4-7 (2018). (In Russian).

9. Dostoevsky, F.M.: Dnevnik pisatelya za 1876 god. Mai-oktyabr' [A writer's diary of the year 1876. May-October] // Polnoe sobranie sochinenii i pisem: V 30 t. Vol. 23. L. Nauka (1981). (In Russian).

10. Aspirantura. Portal dlya aspirantov. Forum. [PhD studies. Portal for $\mathrm{PhD}$ students. Forum] URL: http://www.aspirantura.spb.ru/forum/archive/index.php/t-112.html (Accessed: 04.02.2019).

11. Kolesnikova, N.: "Scientific speech" as continuing education course. // International multidisciplinary scientific conference on social sciences and arts SGEM 2014, Conference proceedings. Bulgaria, Albena, 1-10 Sept., 2014. Sofia. Bulgaria. STEF92 Technology Ltd. Vol. 1. pp. 1019-1024 (2014).

12. Ridnaya, Y.: The criteria for assessing written scientific genres // International multidisciplinary scientific conference on social sciences and arts (SGEM2014): conference proceedings. Bulgaria, Albena, 1-10 Sept. 2014. Sofia. Bulgaria. STEF92 Technology Ltd. Vol. 1. pp. 921-927. (2014).

13. Kolesnikova, N.I., Ridnaya, Yu.V.: Zhanrovaya model' nauchnoi stat'i na russkom i angliiskom jazykakh [The genre model of a scientific paper in the Russian and English languages] // Vysshee obrazovanie v Rossii. 6 (502). pp. 98-106 (2016). (In Russian).

14. Baranov, A.G.: Kogniotipichnost' zhanra [The cognitive nature of a genre] / Stilistika. VI. Opole. (1997). (In Russian).

Information about the authors:

Kolesnikova N.I. - D. Sc. (Education), Associate Professor, Head of the Russian Language Department, Novosibirsk State Technical University (Novosibirsk, Russia). E-mail: nkolesnikova@corp.nstu.ru

Ridnaya Yu.V. - Ph.D., Associate Professor, Department of Foreign Languages for Engineering Faculties, Novosibirsk State Technical University (Novosibirsk, Russia). E-mail: ridnaya@corp.nstu.ru 